\title{
Contribution of glutathione peroxidase 1 (Pro200Leu) single nucleotide polymorphism and serum homocysteine levels in the risk of acute myocardial infarction in Egyptians
}

\author{
Lamia K. Ismail ${ }^{1}$, Mohamed F. Abdel Rahman² ${ }^{*} \mathbb{B}$, Ingy M. Hashad ${ }^{1}$ and Sahar M. Abdel-Maksoud
}

\begin{abstract}
Background: Oxidative stress is among the most common risk factors in the pathogenesis of acute myocardial infarction (AMI). Glutathione peroxidase 1 enzyme coded by the GPX1 gene plays an essential role in reducing oxidative stress. Previous studies correlated the GPX1 (Pro200Leu) single nucleotide polymorphism (SNP) with AMI incidence. Elevated homocysteine (Hcy) levels induce oxidative stress and are considered an independent risk factor for AMI. Evidence showed a complex relationship between Hcy and GPx-1 activity. This study examined the association of the common (Pro200Leu) SNP in GPX1 with AMI incidence in an Egyptian population. This study is the first to check this association in an Egyptian population. Moreover, the association between serum Hcy and the incidence of AMI was checked, and the novelty was to statistically correlate GPX1 Pro200Leu genotypes with serum Hcy levels in patients and control subjects. Hundred control subjects and hundred and twenty AMI patients were genotyped using PCR-RFLP analysis. An ELISA was used to measure serum Hcy levels.

Results: The GPX1 (Pro200Leu) genotype distribution and allele frequency were not significantly different between patients and control subjects $(P=0.60$ and $P=0.62$, respectively). Serum levels of Hcy were significantly elevated in patients compared to control subjects $(P \leq 0.0001)$. However, no significant difference was observed in serum Hcy levels among different GPX1 genotypes in neither patients nor control subjects.
\end{abstract}

Conclusions: The minor T allele of GPX1 Pro200Leu is not associated with AMI risk in this Egyptian population. However, high homocysteine serum levels might contribute independently to the risk of AMI. Finally, Hcy levels were not significantly different in homozygous minor TT compared to homozygous wild CC.

Keywords: Acute myocardial infarction, Oxidative stress, Glutathione peroxidase 1, Homocysteine, Single nucleotide polymorphism

\section{Background}

Cardiovascular diseases (CVDs) are the pre-eminent cause of death globally. They are significant health problems, not only due to high incidence but also due to the

\footnotetext{
*Correspondence: m.farouk@gaf.edu.eg

2 Department of Biology and Biochemistry, School of Life and Medical Sciences, University of Hertfordshire Hosted by Global Academic

Foundation, Cairo, Egypt

Full list of author information is available at the end of the article
}

socioeconomic burden associated with them. Acute myocardial infarction (AMI) is one of the most common CVDs that cause death worldwide [1]. The initial trigger of AMI is mainly irreversible myocardial necrosis that is secondary to prolonged ischemia. The disparity between the myocardial blood supply and demand leads to ischemia [2]. Previous studies showed the involvement of oxidative stress-mediated by reactive oxygen species (ROS) in the pathogenesis of AMI. The exact mechanism by which ROS contributes to AMI is still uncertain; 
however, the most common hypothesized mechanism is that ROS, mainly hydrogen peroxide $\left(\mathrm{H}_{2} \mathrm{O}_{2}\right)$, leads to nitric oxide (NO) insufficiency by converting it to inactive peroxynitrite. $\mathrm{NO}$ is the most potent vasodilator. $\mathrm{NO}$ also alters the adherence of the platelets and leukocytes to the endothelial membrane and improves the barrier function of the endothelium [3].

The glutathione peroxidase (GPx) family are the fundamental antioxidant enzymes in humans [4]. The GPx family consists of eight isoforms named from GPx-1 to GPx-8; each isoform has distinct subcellular localization. The principal role of these enzymes is to convert hydrogen and lipid peroxides to their reduced form, water $\left(\mathrm{H}_{2} \mathrm{O}\right)$ and alcohol $(\mathrm{LOH})$, respectively. Glutathione peroxidase $1(\mathrm{GPx}-1)$ is the most abundant intracellular isoform [4-6]. The cardioprotective role of GPx-1 is manifested by preventing oxidative stress-induced atherosclerosis $[7,8]$. This is attained by reducing the availability of ROS, so low-density lipoprotein (LDL) becomes less prone to be oxidized to oxidized LDL (Ox-LDL), which is the fundamental component of the atherosclerotic plaque and the necrotic core $[8,9]$. Furthermore, it regulates $\mathrm{NO}$ bioavailability by decreasing the levels of hydrogen and lipid peroxides, hence decreasing the susceptibility of NO inactivation to peroxynitrite [10]. The GPX1 gene maps chromosome 3p21. The Pro200Leu single nucleotide polymorphism (SNP) (rs1050450) is a missense mutation that occurs on exon two where the wild allele $C$ is substituted by the T allele (NM_000581.4:c.599C $>$ T) resulting in the amino acid change of Pro to Leu $[6,11]$ that impairs the enzyme activity $[12,13]$. This SNP was previously associated with CVD risk in various ethnicities [14-17].

Homocysteine (Hcy) is a non-essential amino acid. It shows structural homology to cysteine amino acid yet with an additional methylene bridge (-CH2-) [18]. The physiological role of Hcy is debatable and not well known, unlike its toxicity which is mainly due to the covalent interaction between Hcy and the proteins which alter their functions [19]. Elevated Hcy levels are known as hyperhomocysteinemia (HHcy) [20]. Several studies showed a correlation between HHcy and oxidative stress [19, 21]. HHcy-induced oxidative stress can be classified into direct and indirect mechanisms. The direct mechanism involves Hcy being auto-oxidized to homocysteine, releasing $\mathrm{H}_{2} \mathrm{O}_{2}$ as a by-product [22], while the indirect mechanisms involve HHcy inducing ROS generation in several ways. HHcy leads to uncoupling of eNOS and increases xanthine oxidase and NADPH oxidase activity [23-25]; all lead to an increase in superoxide anion generation. The indirect mechanism also involves HHcy downregulating several antioxidant enzymes, mainly GPx-1, as well as depleting its substrate glutathione [10, 26, 27], hence decreasing the antioxidant effect and increasing the oxidative stress. Several experimental and clinical evidence has demonstrated a unique and complex relationship between Hcy and GPx-1 activity. Extreme HHcy inhibited GPx-1 activity in both in vivo and in vitro [28] by a mechanism involving downregulation of translation, which may contribute to the proatherogenic and prothrombic effects of Hcy [26]. Also, individuals with high GPx-1 activity are less susceptible to Hcy damaging effects [29].

Given the above findings, this study examined the association between GPX1 Pro200Leu common SNP and the risk of AMI in an Egyptian population, besides the correlation between serum Hcy levels and the risk of AMI, in addition to statistically correlating GPX1 Pro200Leu different genotypes with the levels of Hcy in control subjects and AMI patients.

\section{Methods}

\section{Study subjects}

Hundred and twenty AMI patients were recruited for this study. The blood samples were collected from patients admitted to the intensive care unit of the National Heart Institute, Imbaba, Giza; El Demerdash Hospital, Cairo, Egypt. All recruited patients were unrelated. Patients were only included if they have been diagnosed with AMI for the first time, confirmed by electrocardiogram and elevated cardiac markers. The samples were drawn within the first $6 \mathrm{~h}$ from the myocardial infarction episode. The patients were divided into fifty-five females with an age range of 46-60 years and sixty-five males with an age range of $44-60$ years.

For the control subjects, hundred healthy individuals were included in this study. All individuals were unrelated, and the samples were collected from the blood bank of 57357 Hospital, Cairo, Egypt. The individuals included forty females with an age range of 41-57 years and sixty males with an age range of $42-58$ years. Subjects were only included in this study if they had no history of AMI or any other cardiovascular diseases besides having a controlled blood pressure of 120/70 $\mathrm{mmHg}$.

The exclusion criteria included any other acute or chronic diseases such as diabetes mellitus, renal or hepatic diseases, cancer, or any other CVDs. This criterion was applied to all study participants. The participants filled out medical reports, which were used to obtain information regarding their family history and lifestyle.

All the procedures comply with the ethical standards of German University in Cairo ethics committee and the 1964 Helsinki Declaration. Written consent was obtained from all study participants. 


\section{Sample collection}

Four milliliters of blood samples was collected. The samples were allowed to clot at room temperature for $30 \mathrm{~min}$ [30] followed by centrifugation at $2500 \mathrm{rpm}$ for $10 \mathrm{~min}$ at $4{ }^{\circ} \mathrm{C}$ to obtain the serum. The serum was then stored at $-20^{\circ} \mathrm{C}$ for Hcy determination.

Whole blood was used for DNA extraction using DNA Blood GeneJET Mini Kits (Thermo Scientific). The extraction was carried out based on the manufacturer's instructions. Briefly, proteinase $\mathrm{K}$ and lysis buffer were added to the blood sample to break down nuclear and cellular membranes, releasing the DNA. The released DNA was then allowed to bind specifically to the silicagel membrane of the GeneJET mini spin column while contaminants were washed through. The DNA was eluted via elution buffer provided with the kit. Then, the purity of the eluted DNA was assessed using Nanodrop and was quantified using Qubit. The extracted, pure DNA was used for genotyping the GPX1 Pro200Leu SNP using polymerase chain reaction-restriction fragment length polymorphism (PCR-RFLP) [31].

\section{The GPX1 Pro200Leu SNP genotyping by PCR-RFLP}

The forward primer used for the amplification of the 230bp fragment was $5^{\prime}$-TTATGACCGACCCCAAGCTCA$3^{\prime}$ while the reverse primer was $5^{\prime}$-ACAGCAGCACTG CAACTGCC-3' [32]. A $1 \mu \mathrm{l}$ of Hae III restriction enzyme was used to digest the obtained PCR product. The PCR digests were then loaded on $3 \%$ agarose gel and visualized under UV after staining with ethidium bromide. In the case of the minor allele T, 148 and $82 \mathrm{bp}$ band sizes are obtained while for the wild allele C, 88, 82, and 60bp bands are obtained as shown in Fig. 1.

\section{Measuring serum Hcy concentrations}

Serum Hcy levels were quantified using the human Hcy enzyme-linked immunosorbent assay (ELISA) kit provided by Axis-Shield, Dundee, UK.

\section{Lipid profiling for study participants}

The serum samples were also used to measure the levels of triglycerides (TG) and total cholesterol (TC) via an enzymatic colorimetric method using kits provided by Diamond diagnostics, Egypt.

\section{Statistical analysis}

All the statistical analyses were performed using GraphPad Prism software (GraphPad Software, Inc). All continuous data were presented as median (IQR). The differences between the two study groups were assessed using either the nonparametric student $t$-test (MannWhitney) or the nonparametric one-way ANOVA (Kruskal-Wallis). The odds ratio (OR) with 95\% confidence interval (CI) were used to check whether the minor allele $\mathrm{T}$ is associated with increased risk of AMI or not. A two-tailed $P$-value $\leq 0.05$ was used as the significance threshold for all tests. However, $P>0.05$ indicated no deviation from the Hardy-Weinberg equilibrium (HWE).

\section{Results \\ Demographics of the study cohort}

The demographics of the study cohort, serum TC, TG, and Hcy levels are shown in Table 1.

\section{Genotyping of the Pro200Leu SNP}

The pattern of the genotype distribution was not significantly different between AMI patients and control subjects (Mann-Whitney test, $P=0.60$ ). Similarly, there was

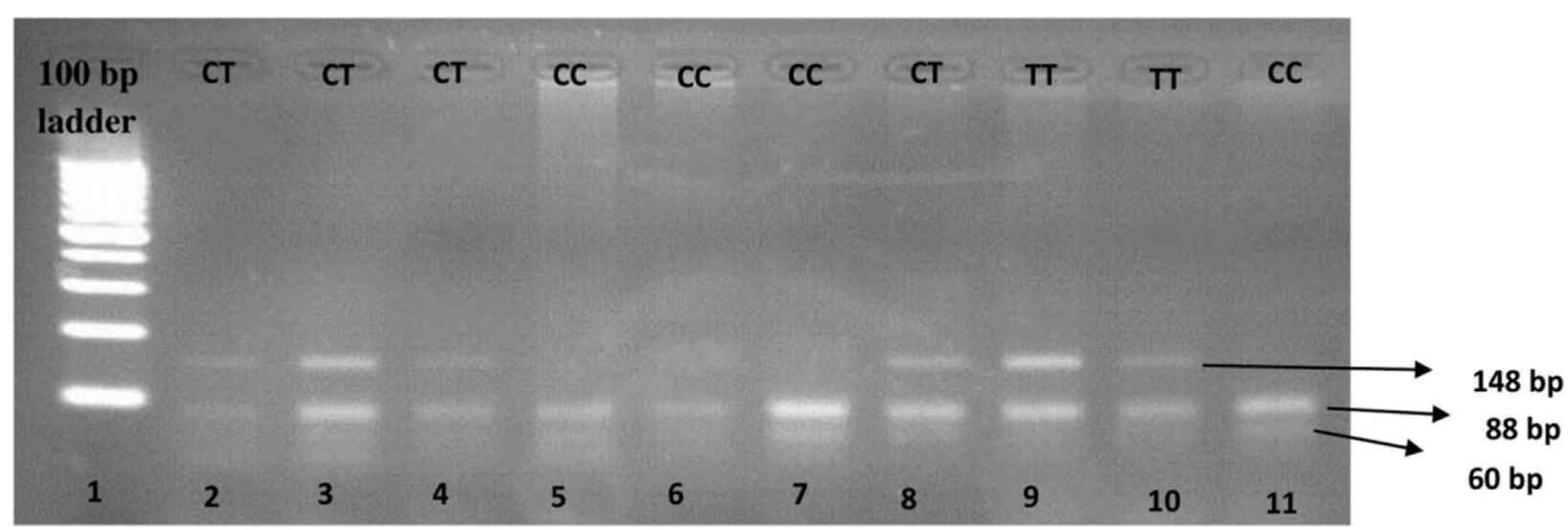

Fig. 1 The gel shows all the possible genotypes. The samples (50 ng) were loaded and ran against a 100-bp DNA ladder marker. In the case of homozygous wild CC as in lanes 5, 6, 7, and 11, 3 bands were obtained ( 88,82 , and 60bps). In the case of heterozygous CT as in lanes 2, 3, 4, and 8, 4 bands were obtained (148, 88, 82, and 60bps), while for homozygous minor TT as in lanes 9 and 10, only 2 bands were obtained (148 and $82 \mathrm{bps})$ 
Table 1 Demographics of the study participants

\begin{tabular}{lll}
\hline Groups & Control subjects & AMI patients \\
\hline Number (male/female) & $100(60 / 40)$ & $120(65 / 55)$ \\
Age range & $41-58$ & $44-60$ \\
Serum total cholesterol $(\mathbf{m g} / \mathbf{d L})$ & $175(23)$ & $222(59)$ \\
Serum triglycerides $(\mathbf{m g} / \mathbf{d L})$ & $108(44)$ & $149(67)$ \\
Serum homocysteine $(\boldsymbol{\mu m o l e} / \mathbf{L})$ & $15(5.5)$ & $29(9.5)$
\end{tabular}

Categorical data are presented as number. Continuous data are presented as median (IQR)

no significant difference in the allele frequencies between the two groups (Mann-Whitney, $P=0.62$ ). Carriers of the risk allele $\mathrm{T}$ allele $(\mathrm{CT}+\mathrm{TT})$ did not show a higher risk for incidence of AMI compared to wild CC genotype $(O R=0.8623 ; P=0.5862)$, as illustrated in Table 2.

\section{Levels of Hcy in serum}

The AMI group had up to a 1.90-fold significant increase in median serum levels of Hcy compared to control subjects $(P \leq 0.0001)$ as shown in Fig. 2 .

\section{Correlation of genotypes with serum Hcy levels in study groups}

There was no significant correlation between different genotypes and median serum Hcy levels in neither AMI patients nor control subjects $(P=0.186$ and $P=0.373$, respectively) as shown in Fig. 3.

\section{TG and TC levels between study groups}

The AMI group had up to 1.38 -fold significant increase in the median serum TG concentration compared to controls $(P<0.0001)$. Similarly, a significant $(P<0.0001)$ increase up to 1.27 -fold was observed in the median serum TC concentration in the AMI group compared to controls.

\section{Discussion}

Correlation between GPX1 Pro200Leu SNP and risk of AMI Under normal physiological conditions, GPx-1 reduces oxidative stress tremendously [5]. Cheng et al. reported that patients with impaired GPx-1 activity are more prone to develop AMI [33]. As far as we know, this study

Table 2 Odds ratio (OR) with 95\% confidence intervals (Cl) for GPX1 Pro200Leu in study groups

\begin{tabular}{lllll}
\hline $\begin{array}{l}\text { GPX1 } \\
\text { Pro200Leu }\end{array}$ & $\begin{array}{l}\text { AMI } \\
\text { patients }(\boldsymbol{n} \\
=\mathbf{1 2 0})\end{array}$ & $\begin{array}{l}\text { Control } \\
\text { subjects }(\boldsymbol{n}=\mathbf{1 0 0})\end{array}$ & $\begin{array}{l}\text { OR } \\
\mathbf{( 9 5 \%} \boldsymbol{C l})\end{array}$ & $\begin{array}{l}\boldsymbol{P} \text {-value } \\
\end{array}$ \\
\hline CT+TT & 52 & 45 & 0.8623 & 0.5862 \\
CC & 68 & 55 & $(0.5058-1.470)$ & \\
\hline
\end{tabular}

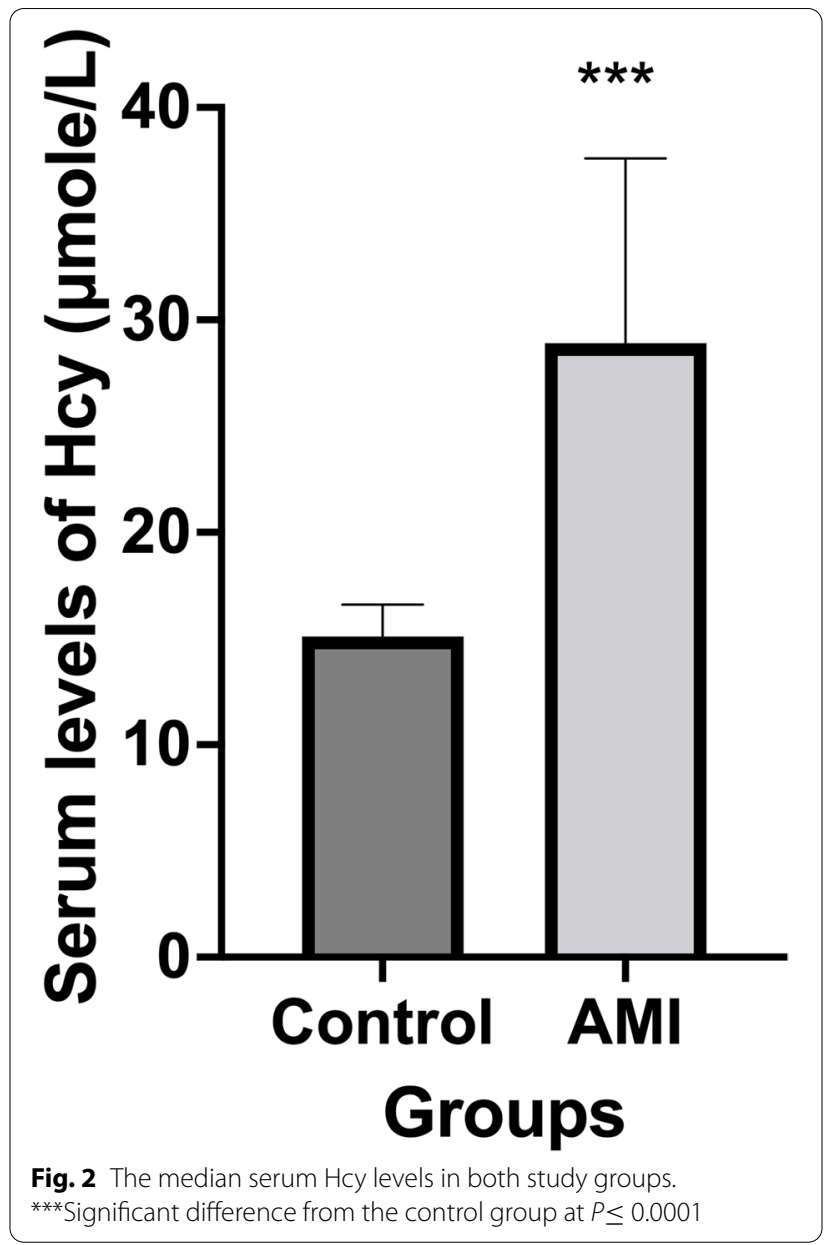

is the first to clinically investigate the possible association of GPX1 (Pro200Leu) SNP and the risk of AMI in an Egyptian population. The current study results showed no significant difference in neither the GPX1 genotype distribution nor the allele frequency between AMI and control groups suggesting that the GPX1 Pro200Leu SNP is not associated with the risk of AMI. Our results showed consistency with studies done on Chinese [14], Swedish [15], Indian [16], and Russian populations [17]. However, our results contrasted the one done on Japanese [11].

A suggested explanation for the above significant correlation between this SNP and AMI is that the Pro to Leu amino acid change could alter the activity of the enzyme [12] since the Leu variant was previously associated with a reduction in the enzyme activity $[11,34]$. The GPx-1 enzyme is abundant in endothelial cells and macrophages; therefore, the decreased activity is expected to increase the sensitivity of the vessels to oxidative stress and will be more prone to oxidative stress-induced atherosclerosis [32]. The above conflicting findings may be 


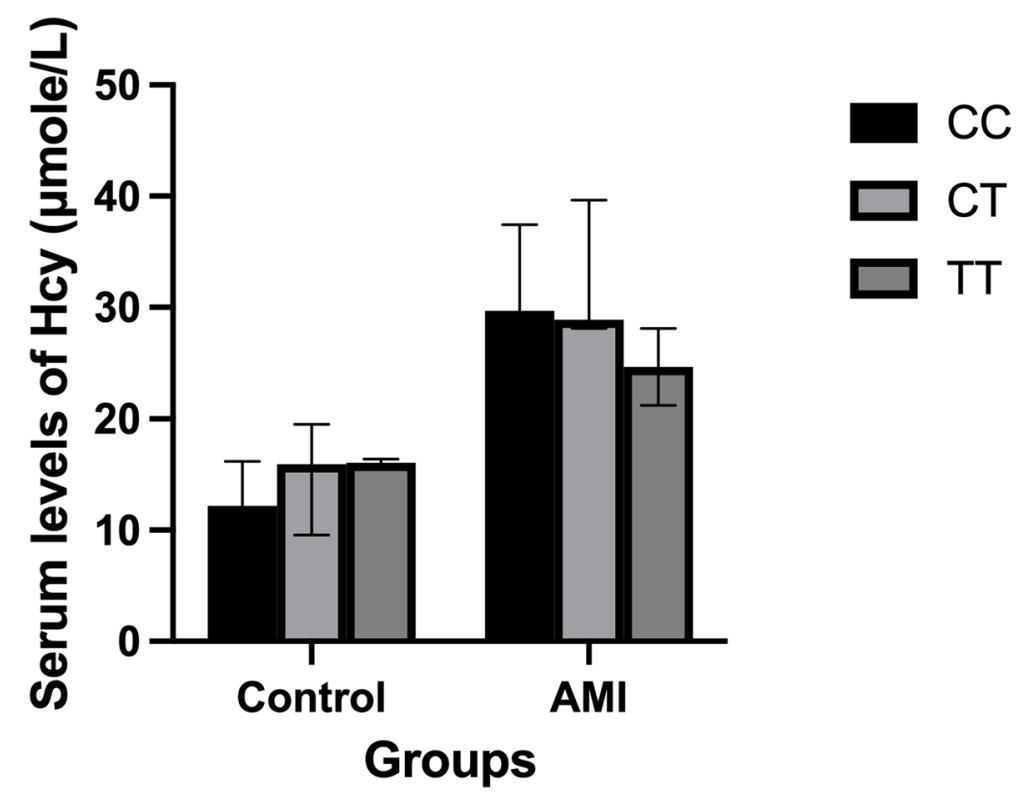

Fig. 3 The median serum Hcy concentrations among all genotypes in both control and AMI

attributed to the differences in ethnicities, trial numbers, different methods applied, sampling schemes, and the different environmental effects $[26,35]$.

\section{Serum Hcy levels}

Hcy is a non-essential amino acid with an extra sulfur; the main pathway for Hcy synthesis is methionine demethylation [18]. Hcy levels are maintained via two pathways, either remethylation or trans-sulfuration [36]. Hcy levels above $16 \mu$ mole/L are known as HHcy [37] and were previously shown to be independently a risk factor for various diseases, including CVDs [38-40].

In this study, the median Hcy concentration was significantly higher in the AMI group compared to the control group $(P \leq 0.0001)$. This significant correlation can be due to several effects; Hcy triggers the endothelium to synthesize and release pro-coagulant factors [41]. It also enhances the auto-oxidation of LDL to Ox-LDL [42], promotes vascular thrombosis by reducing the activation of protein $\mathrm{C}$, initiates the aggregation of the platelets, and stimulates smooth muscle cell proliferation [38, 43]. Our results were consistent with those observed in several other ethnicities [44-46].

\section{Correlation between SNP and Hcy in study subjects}

Experimental evidence showed that GPx-1 regulates Hcy-induced cardiovascular risk and that Hcy attenuates the ability of the cell to detoxify hydrogen peroxide by inhibiting the intracellular activity of GPx-1 [29]. Hcy also downregulates translation [26]. Therefore, a possible correlation between the rs1050450 variant and serum Hcy levels was hypothesized.

In the current study, the GPX1 Pro200Leu SNP and the Hcy serum levels were correlated in neither the AMI $(P=0.186)$ nor the controls $(P=0.373)$. Our study was the first to correlate the SNP and Hcy serum levels in humans. However, our results were consistent with Dayal et al's findings in mice in which Hcy levels were not associated with the GPX1 genotypes [47].

\section{Conclusion}

We can conclude from this study that GPX1 Pro200Leu SNP was not significantly associated with AMI in an Egyptian population. However, Hcy's role in the incidence of AMI was confirmed since AMI patients had significantly 1.90 -fold higher median serum levels of Hcy compared to healthy control subjects, while the novel correlation between Hcy serum levels and the SNP showed no significant difference in neither healthy control subjects nor AMI patients.

\section{Abbreviations}

AMI: Acute myocardial infarction; bp: Base pairs; Cl: Confidence interval; CVDs: Cardiovascular diseases; DNA: Deoxyribonucleic acid; ELISA: Enzyme-linked immunosorbent assay; GPx: Glutathione peroxidase; GPx-1: Glutathione peroxidase 1; Hcy: Homocysteine; HHcy: Hyperhomocysteinemia; HWE: HardyWeinberg equilibrium; IQR: Inter-quartile range; LDL: Low-density lipoprotein; Leu: Leucine; NO: Nitric oxide; OR: Odds ratio; Ox-LDL: Oxidized low-density lipoprotein; PCR-RFLP: Polymerase chain reaction-fragment length polymorphism; Pro: Proline; ROS: Reactive oxygen species; rpm: Rotation per minute; SNP: Single nucleotide polymorphism; TC: Total cholesterol; TG: Triglycerides; UV: Ultraviolet 


\section{Acknowledgements \\ Not applicable}

\section{Authors' contributions}

Concept: IMH and MFA; methodology: LKI, MFA, and IMH; writing: LKI; writing, review, and editing: IMH and MFA; supervision: IMH, MFA, and SMA. All authors read and approved the final manuscript.

\section{Funding}

This research did not receive any specific grant from funding agencies in the public, commercial, or not-for-profit sectors.

\section{Availability of data and materials}

The datasets used and/or analyzed during the current study are available from the corresponding author on reasonable request.

\section{Declarations}

\section{Ethics approval and consent to participate}

The project was evaluated by the Ethics Committee of the German University in Cairo (Committee reference number not applicable) with regard to participation of human patients or animals and/or clinical samples obtained from humans or animals, and with the respect of anonymity guaranteed to patients from whom any samples are being obtained. Written informed consent was obtained from each participant in the study that abided by the Helsinki Declaration.

\section{Consent for publication}

Not applicable. No data that compromises anonymity is presented.

\section{Competing interests}

The authors declare that they have no competing interests.

\section{Author details}

${ }^{1}$ Clinical Biochemistry Department, Faculty of Pharmacy and Biotechnology, the German University, Cairo, Egypt. ${ }^{2}$ Department of Biology and Biochemistry, School of Life and Medical Sciences, University of Hertfordshire Hosted by Global Academic Foundation, Cairo, Egypt.

Received: 17 September 2021 Accepted: 20 January 2022

Published online: 09 February 2022

\section{References}

1. Virani SS, Alonso A, Benjamin EJ, Bittencourt MS, Callaway CW, Carson AP, Chamberlain AM, Chang AR, Cheng S, Delling FN, Djousse L, Elkind MSV, Ferguson JF, Fornage M, Khan SS, Kissela BM, Knutson KL, Kwan TW, Lackland DT, Lewis TT, Lichtman JH, Longenecker CT, Loop MS, Lutsey PL, Martin SS, Matsushita K, Moran AE, Mussolino ME, Perak AM, Rosamond WD, Roth GA, Sampson UKA, Satou GM, Schroeder EB, Shah SH, Shay CM, Spartano NL, Stokes A, Tirschwell DL, VanWagner LB, Tsao CW (2020) Heart disease and stroke statistics-2020 update: a report from the American Heart Association. Circulation 141:e139-e596

2. Saleh M and Ambrose J A (2018) Understanding myocardial infarction. F1000Res 7:

3. Griendling KK, FitzGerald GA (2003) Oxidative stress and cardiovascular injury: part l: basic mechanisms and in vivo monitoring of ROS. Circulation 108:1912-1916

4. Shiomi T, Tsutsui H, Matsusaka H, Murakami K, Hayashidani S, Ikeuchi M, Wen J, Kubota T, Utsumi H, Takeshita A (2004) Overexpression of glutathione peroxidase prevents left ventricular remodeling and failure after myocardial infarction in mice. Circulation 109:544-549

5. Lubos E, Loscalzo J, Handy DE (2011) Glutathione peroxidase-1 in health and disease: from molecular mechanisms to therapeutic opportunities. Antioxid Redox Signal 15:1957-1997

6. Jefferies S, Kote-Jarai Z, Goldgar D, Houlston R, Frazer-Williams MJ, A'Hern R, Eeles R, Henk J, Gore M, Rhys-Evans P, Archer D, Bishop K, Solomon E, Hodgson S, McGurk M, Hibbert J, O'Connell M, Partridge M, Chevretton E, Calman F, Saunders M, Shotton K, Brown A, Whittaker S, Foulkes W (2005) Association between polymorphisms of the GPX1 gene and second primary tumours after index squamous cell cancer of the head and neck. Oral Oncol 41:455-461

7. Toussaint O, Houbion A, Remacle J (1993) Relationship between the critical level of oxidative stresses and the glutathione peroxidase activity. Toxicology 81:89-101

8. Suzen HS, Gucyener E, Sakalli O, Uckun Z, Kose G, Ustel D, Duydu Y (2010) CAT C-262T and GPX1 Pro198Leu polymorphisms in a Turkish population. Mol Biol Rep 37:87-92

9. Blankenberg S, Rupprecht HJ, Bickel C, Torzewski M, Hafner G, Tiret L, Smieja M, Cambien F, Meyer J, Lackner KJ (2003) Glutathione peroxidase 1 activity and cardiovascular events in patients with coronary artery disease. N Engl J Med 349:1605-1613

10. Upchurch GR Jr, Welch GN, Fabian AJ, Freedman JE, Johnson JL, Keaney JF Jr, Loscalzo J (1997) Homocyst(e)ine decreases bioavailable nitric oxide by a mechanism involving glutathione peroxidase. J Biol Chem 272:17012-17017

11. Hamanishi T, Furuta $H$, Kato H, Doi A, Tamai M, Shimomura H, Sakagashira S, Nishi M, Sasaki H, Sanke T, Nanjo K (2004) Functional variants in the glutathione peroxidase-1 (GPx-1) gene are associated with increased intima-media thickness of carotid arteries and risk of macrovascular diseases in Japanese type 2 diabetic patients. Diabetes 53:2455-2460

12. Ravn-Haren G, Olsen A, Tjønneland A, Dragsted LO, Nexø BA, Wallin H, Overvad K, Raaschou-Nielsen O, Vogel U (2006) Associations between GPX1 Pro198Leu polymorphism, erythrocyte GPX activity, alcohol consumption and breast cancer risk in a prospective cohort study. Carcinogenesis 27:820-825

13. Forgione MA, Weiss N, Heydrick S, Cap A, Klings ES, Bierl C, Eberhardt RT, Farber HW, Loscalzo J (2002) Cellular glutathione peroxidase deficiency and endothelial dysfunction. Am J Physiol Heart Circ Physiol 282:H1255-H1261

14. Chen H, Yu M, Li M, Zhao R, Zhu Q, Zhou W, Lu M, Lu Y, Zheng T, Jiang J, Zhao W, Xiang K, Jia W, Liu L (2012) Polymorphic variations in manganese superoxide dismutase (MnSOD), glutathione peroxidase-1 (GPX1), and catalase (CAT) contribute to elevated plasma triglyceride levels in Chinese patients with type 2 diabetes or diabetic cardiovascular disease. Mol Cell Biochem 363:85-91

15. Forsberg L, de Faire U, Marklund SL, Andersson PM, Stegmayr B, Morgenstern R (2000) Phenotype determination of a common Pro-Leu polymorphism in human glutathione peroxidase 1. Blood Cells Mol Dis 26:423-426

16. Ramprasath T, Murugan PS, Kalaiarasan E, Gomathi P, Rathinavel A, Selvam GS (2012) Genetic association of glutathione peroxidase-1 (GPx-1) and $\mathrm{NAD}(\mathrm{P}) \mathrm{H}$ :quinone oxidoreductase 1 (NQO1) variants and their association of CAD in patients with type-2 diabetes. Mol Cell Biochem 361:143-150

17. Sergeeva TV, Chistiakov DA, Kobalava ZD, Moiseev VS (2001) Polymorphism of catalase and glutathione peroxidase genes in macrovascular complications in patients with non-insulin-dependent diabetes mellitus and hypertension. Genetika 37:418-421

18. Malinow MR, Bostom AG, Krauss RM (1999) Homocyst(e)ine, diet, and cardiovascular diseases: a statement for healthcare professionals from the Nutrition Committee, American Heart Association. Circulation 99:178-182

19. Perła-Kaján J, Twardowski T, Jakubowski H (2007) Mechanisms of homocysteine toxicity in humans. Amino Acids 32:561-572

20. Herrmann W (2006) Significance of hyperhomocysteinemia. Clin Lab 52:367-374

21. Jakubowski H (2006) Pathophysiological consequences of homocysteine excess. J Nutr 136:1741S-1749S

22. Sengupta S, Wehbe C, Majors AK, Ketterer ME, DiBello PM, Jacobsen DW (2001) Relative roles of albumin and ceruloplasmin in the formation of homocystine, homocysteine-cysteine-mixed disulfide, and cystine in circulation. J Biol Chem 276:46896-46904

23. Doshi SN, McDowell IF, Moat SJ, Payne N, Durrant HJ, Lewis MJ, Goodfellow J (2002) Folic acid improves endothelial function in coronary artery disease via mechanisms largely independent of homocysteine lowering. Circulation 105:22-26

24. Bagi Z, Ungvari Z, Koller A (2002) Xanthine oxidase-derived reactive oxygen species convert flow-induced arteriolar dilation to constriction in hyperhomocysteinemia: possible role of peroxynitrite. Arterioscler Thromb Vasc Biol 22:28-33

25. Petras M, Tatarkova Z, Kovalska M, Mokra D, Dobrota D, Lehotsky J, Drgova A (2014) Hyperhomocysteinemia as a risk factor for the neuronal system disorders. J Physiol Pharmacol 65:15-23

26. Handy DE, Zhang Y, Loscalzo J (2005) Homocysteine down-regulates cellular glutathione peroxidase (GPx1) by decreasing translation. J Biol Chem 280:15518-15525 
27. Weiss N, Heydrick S, Zhang YY, Bierl C, Cap A, Loscalzo J (2002) Cellular redox state and endothelial dysfunction in mildly hyperhomocysteinemic cystathionine beta-synthase-deficient mice. Arterioscler Thromb Vasc Biol 22:34-41

28. Durmaz A, Dikmen N (2007) Homocysteine effects on cellular glutathione peroxidase (GPx-1) activity under in vitro conditions. J Enzyme Inhib Med Chem 22:733-738

29. Schnabel R, Lackner KJ, Rupprecht HJ, Espinola-Klein C, Torzewski M, Lubos E, Bickel C, Cambien F, Tiret L, Münzel T, Blankenberg S (2005) Glutathione peroxidase-1 and homocysteine for cardiovascular risk prediction: results from the AtheroGene study. J Am Coll Cardiol 45:1631-1637

30. Tuck MK, Chan DW, Chia D, Godwin AK, Grizzle WE, Krueger KE, Rom W, Sanda M, Sorbara L, Stass S, Wang W, Brenner DE (2009) Standard operating procedures for serum and plasma collection: early detection research network consensus statement standard operating procedure integration working group. J Proteome Res 8:113-117

31. Dai S, Long Y (2015) Genotyping analysis using an RFLP assay. Methods Mol Biol 1245:91-99

32. Nemoto M, Nishimura R, Sasaki T, Hiki Y, Miyashita Y, Nishioka M, Fujimoto K, Sakuma T, Ohashi T, Fukuda K, Eto Y, Tajima N (2007) Genetic association of glutathione peroxidase- 1 with coronary artery calcification in type 2 diabetes: a case control study with multi-slice computed tomography. Cardiovasc Diabetol 6:23

33. Cheng ML, Chen CM, Ho HY, Li JM, Chiu DT (2009) Effect of acute myocardial infarction on erythrocytic glutathione peroxidase 1 activity and plasma vitamin e levels. Am J Cardiol 103:471-475

34. Shuvalova YA, Kaminnyi Al, Meshkov AN, KukharchukVV (2010) Pro198Leu polymorphism of GPX-1 gene and activity of erythrocytic glutathione peroxidase and lipid peroxidation products. Bull Exp Biol Med 149:743-745

35. Lei C, Niu XL, Wei J, Zhu JH, Zhu Y (2010) Polymorphisms in the glutathione peroxidase-1 gene associated with increased risk of Keshan disease. Zhonghua Yu Fang Yi Xue Za Zhi 44:617-621

36. Biasioli S, Schiavon R (2000) Homocysteine as a cardiovascular risk factor. Blood Purif 18:177-182

37. Ansari R, Mahta A, Mallack E, Luo JJ (2014) Hyperhomocysteinemia and neurologic disorders: a review. J Clin Neurol 10:281-288

38. Baszczuk A, Kopczyński Z (2014) Hyperhomocysteinemia in patients with cardiovascular disease. Postepy Hig Med Dosw (Online) 68:579-589

39. Maldonado C, Soni CV, Todnem ND, Pushpakumar S, Rosenberger D, Givvimani S, Villafane J, Tyagi SC (2010) Hyperhomocysteinemia and sudden cardiac death: potential arrhythmogenic mechanisms. Curr Vasc Pharmacol 8:64-74

40. Ganguly P, Alam SF (2015) Role of homocysteine in the development of cardiovascular disease. Nutr J 14:6

41. Lentz SR (2005) Mechanisms of homocysteine-induced atherothrombosis. J Thromb Haemost 3:1646-1654

42. Heinecke JW, Rosen H, Suzuki LA, Chait A (1987) The role of sulfur-containing amino acids in superoxide production and modification of low density lipoprotein by arterial smooth muscle cells. J Biol Chem 262:10098-10103

43. Clarke R, Daly L, Robinson K, Naughten E, Cahalane S, Fowler B, Graham I (1991) Hyperhomocysteinemia: an independent risk factor for vascular disease. N Engl J Med 324:1149-1155

44. Naureen A, Munazza B, Shaheen R, Khan SA, Fatima F (2012) Serum homocysteine as a risk factor for coronary heart disease. J Ayub Med Coll Abbottabad 24:59-62

45. Shenoy V, Mehendale V, Prabhu K, Shetty R, Rao P (2014) Correlation of serum homocysteine levels with the severity of coronary artery disease. Indian J Clin Biochem 29:339-344

46. Amiri Majd A, Rezaei M, Goodarzi M, Homayoonfar S (2007) Some biomarkers in acute myocardial infarction. J Res Health Sci 7:11-19

47. Dayal S, Brown KL, Weydert CJ, Oberley LW, Arning E, Bottiglieri T, Faraci FM, Lentz SR (2002) Deficiency of glutathione peroxidase-1 sensitizes hyperhomocysteinemic mice to endothelial dysfunction. Arterioscler Thromb Vasc Biol 22:1996-2002

\section{Publisher's Note}

Springer Nature remains neutral with regard to jurisdictional claims in published maps and institutional affiliations.

\section{Submit your manuscript to a SpringerOpen ${ }^{\circ}$ journal and benefit from:}

- Convenient online submission

- Rigorous peer review

- Open access: articles freely available online

- High visibility within the field

- Retaining the copyright to your article

Submit your next manuscript at $\boldsymbol{\nabla}$ springeropen.com 